\title{
A Novel Mutation in the type I $\alpha$ Regulatory Subunit of Protein Kinase A (PRKAR1A) in a Cushing's Syndrome Patient with Primary Pigmented Nodular Adrenocortical Disease
}

\author{
Ryohei Mineo ${ }^{1}$, Sachiko Tamba ${ }^{1}$, Yuya Yamada ${ }^{1}$, Tomonori Okita ${ }^{1}$, Yusuke Kawachi ${ }^{1}$, \\ Reiko Mori ${ }^{1}$, Mitsuaki Kyo ${ }^{1}$, Kenji Saisho ${ }^{1}$, Yohei Kuroda ${ }^{1}$, Koji Yamamoto ${ }^{1}$, \\ Akiko Furuya $^{2}$, Tokuo Mukai ${ }^{3}$, Takashi Maekawa ${ }^{4}$, Yasuhiro Nakamura ${ }^{4}$, \\ Hironobu Sasano ${ }^{4}$ and Yuji Matsuzawa ${ }^{1}$
}

\begin{abstract}
A 40-year-old man presented with Cushing's syndrome due to bilateral adrenal hyperplasia with multiple nodules. Computed tomography scan results were atypical demonstrating an enlargement of the bilateral adrenal glands harboring multiple small nodules, but the lesion was clinically diagnosed to be primary pigmented nodular adrenocortical disease (PPNAD) based on both endocrinological test results and his family history. We performed bilateral adrenalectomy and confirmed the diagnosis histologically. An analysis of the patient and his mother's genomic DNA identified a novel mutation in the type I $\alpha$ regulatory subunit of protein kinase A (PRKAR1A) gene; p.E17X (c.49G>T). This confirmed the diagnosis of PPNAD which is associated with Carney Complex.
\end{abstract}

Key words: Cushing's syndrome, primary pigmented nodular adrenocortical disease (PPNAD), type I $\alpha$ regulatory subunit of protein kinase A (PRKAR1A)

(Intern Med 55: 2433-2438, 2016)

(DOI: 10.2169/internalmedicine.55.6605)

\section{Introduction}

Primary pigmented nodular adrenocortical disease (PPNAD) is a bilateral adrenocortical disorder characterized by multiple black or brown cortical nodules, and is a rare cause of Cushing's syndrome. In most cases this disease occurs as a part of Carney Complex (CNC). CNC was first reported by Carney et al. in 1985 (1) and it is an autosomal dominant disease with multiple neoplasia syndromes. The inactivating type $\mathrm{I} \alpha$ regulatory subunit of protein kinase $\mathrm{A}$ (PRKARlA) mutations is known to be responsible for CNC. To date, at least 117 pathogenic variants in PRKARlA have been identified, but the genotype-phenotype correlation in
CNC patients remains uncertain. We herein report a case of Cushing's syndrome due to PPNAD and CNC with a novel mutation in PRKARIA.

\section{Case Report}

A 40-year-old man had been treated for 6 years for hypertension and dyslipidemia. Despite the administration of multiple medications, his blood pressure had not been well controlled. In March 2013 he felt generally fatigued and developed pedal edema, and therefore he was admitted to our hospital. He had a history of colon polyps, which had been resected and thus was diagnosed to have early-stage colon cancer by histological examinations. He also suffered multi-

\footnotetext{
${ }^{1}$ Department of Endocrinology and Metabolism, Sumitomo Hospital, Japan, ${ }^{2}$ Department of Pediatrics, Asahikawa Medical University, Japan, ${ }^{3}$ Department of Pediatrics, Asahikawa Kosei General Hospital, Japan and ${ }^{4}$ Department of Pathology, Tohoku University Graduate School of Medicine, Japan

Received for publication September 24, 2015; Accepted for publication March 4, 2016

Correspondence to Dr. Ryohei Mineo, sundaymorning20@me.com
} 
Table 1. Endocrinological Data.

\begin{tabular}{|c|c|c|c|c|}
\hline \multicolumn{5}{|l|}{ Blood sample: } \\
\hline $\mathrm{GH}$ & 0.21 & $\mathrm{ng} / \mathrm{mL}$ & cortisol & $24.1 \mu \mathrm{g} / \mathrm{dL}$ \\
\hline IGF-1 & 158 & $\mathrm{ng} / \mathrm{mL}$ & DHEA-S & $80 \mu \mathrm{g} / \mathrm{dL}$ \\
\hline LH & 1.33 & $\mathrm{mIU} / \mathrm{mL}$ & TSH & $0.67 \mu \mathrm{IU} / \mathrm{mL}$ \\
\hline FSH & 4.27 & $\mathrm{mIU} / \mathrm{mL}$ & FT3 & $2.1 \mathrm{pg} / \mathrm{mL}$ \\
\hline PRL & 10.9 & $\mathrm{ng} / \mathrm{mL}$ & FT4 & $0.8 \mathrm{ng} / \mathrm{dL}$ \\
\hline testosterone & 2.09 & $\mathrm{ng} / \mathrm{mL}$ & PRA & $0.5 \mathrm{ng} / \mathrm{mL} / \mathrm{hr}$ \\
\hline ACTH & $\leq 2.0$ & $\mathrm{pg} / \mathrm{mL}$ & PAC & $79.1 \mathrm{pg} / \mathrm{mL}$ \\
\hline \multicolumn{5}{|l|}{ Urine sample: } \\
\hline U-cortisol & 398.0 & $\mu \mathrm{g} /$ day & U-VMA & $5.12 \mathrm{mg} /$ day \\
\hline U-Adrenaline & 6.0 & $\mu \mathrm{g} /$ day & U-Metanephrine & $0.13 \mathrm{mg} /$ day \\
\hline U-Noradrenaline & 184 & $\mu \mathrm{g} /$ day & U-Normetanephrine & $0.27 \mathrm{mg} /$ day \\
\hline U-Dopamine & 1127 & $\mu \mathrm{g} /$ day & & \\
\hline \multicolumn{5}{|c|}{ Diurnal profile of ACTH and cortisol } \\
\hline Time & $6: 00$ & $11: 30$ & $17: 30$ & $23: 00$ \\
\hline ACTH (pg/mL) & $\leq 2.0$ & $\leq 2.0$ & $\leq 2.0$ & $\leq 2.0$ \\
\hline $\operatorname{cortisol}(\mu \mathrm{g} / \mathrm{dL})$ & 27.1 & 22.6 & 27.4 & 29.4 \\
\hline \multicolumn{5}{|c|}{ Dexamethasone Suppression Test } \\
\hline & before & & after $1 \mathrm{mg}$ & after $8 \mathrm{mg}$ \\
\hline ACTH (pg/mL) & $\leq 2.0$ & & $\leq 2.0$ & $\leq 2.0$ \\
\hline cortisol $(\mu \mathrm{g} / \mathrm{dL})$ & 24.1 & & 23.7 & 28.1 \\
\hline \multicolumn{5}{|c|}{$\begin{array}{l}\text { GH: growth hormone, IGF-1: insulin-like growth factor-1, LH: luteinizing hormone, } \\
\text { FSH: follicle-stimulating hormone, PRL: prolactin, } \\
\text { ACTH: adrenocorticotropic hormone, DHEA-S: dehydroepiandrosterone-sulfate, } \\
\text { TSH: thyroid stimulating hormone, FT3: free triiodothyronine, FT4: free thyroxine, } \\
\text { PRA: plasma renin activity, PAC: plasma aldosterone concentration, } \\
\text { U-VMA: urinary vanillyl mandelic acid }\end{array}$} \\
\hline
\end{tabular}

ple rib fractures on both sides without any obvious contusion. In his family, his mother had been treated for hypertension and osteoporosis, and had an episode of bilateral breast fibroma. In addition, a cousin on his mother's side was diagnosed with Cushing's syndrome due to bilateral nodular adrenocortical disease, and bilateral adrenalectomy had thus been performed at another hospital.

On admission, the patient's height was $167.1 \mathrm{~cm}$, weight was $83.0 \mathrm{~kg}$, and body mass index was 29.7. His blood pressure was $150 / 92 \mathrm{mmHg}$, pulse rate 90 per minute, and body temperature $36.8^{\circ} \mathrm{C}$. Physical examination revealed a Cushingoid appearance, including moon face, facial acne, a buffalo hump, and central obesity. He did not show any red skin striae, but spotty pigmentation was present on his face, upper limbs and chest. Pedal edema was also noted. Routine laboratory findings showed his white blood cell count and transaminase levels to be slightly elevated, while his renal function, electrolytes and lipid levels were within the normal limits. A 75-g oral glucose tolerance test revealed an impaired glucose tolerance; 0 minute: $98 \mathrm{mg} / \mathrm{dL}$ and $120 \mathrm{~min}-$ utes: $177 \mathrm{mg} / \mathrm{dL}$. The endocrinological data are shown in Table 1. The serum aldosterone levels, plasma rennin activity, and 24-hour urinary excretion of catecholamines and their metabolites were within the normal limits except for a slightly elevated urinary excretion level for vanillyl mandelic acid. The serum dehydroepiandrosterone sulfate (DHEAS) concentration was decreased. In addition, the serum cortisol levels were above the normal range and the plasma adrenocorticotropic hormone (ACTH) levels were suppressed throughout the day (Table 1), thus showing a loss of diurnal rhythm. Neither a low dose $(1 \mathrm{mg})$ nor a high dose $(8 \mathrm{mg})$ of dexamethasone could suppress the serum cortisol level on the following morning. During the classical dexamethasone suppression test (Liddle test), no paradoxical increase of urinary 24-h cortisol excretion was observed. Stimulation with glucose, (serum cortisol level; $26.0 \mu \mathrm{g} / \mathrm{dL}$ at 0 minute, peak level of $26.7 \mu \mathrm{g} / \mathrm{dL}$ reached after 60 minutes), gonadotropinreleasing hormone (GnRH) (serum cortisol level; $23.5 \mu \mathrm{g} / \mathrm{dL}$ at 0 minute, peak level of $26.0 \mu \mathrm{g} / \mathrm{dL}$ reached after 120 minutes), thyrotropin-releasing hormone (TRH) (serum cortisol level; $26.9 \mu \mathrm{g} / \mathrm{dL}$ at 0 minute, peak level of $26.9 \mu \mathrm{g} / \mathrm{dL}$ reached after 30 minutes), vasopressin (AVP) (serum cortisol level; $26.1 \mu \mathrm{g} / \mathrm{dL}$ at 0 minute, peak level of $26.8 \mu \mathrm{g} / \mathrm{dL}$ reached after 120 minutes), metoclopramide $(24.6 \mu \mathrm{g} / \mathrm{dL}$ at 0 minute, peak level of $24.5 \mu \mathrm{g} / \mathrm{dL}$ reached after $60 \mathrm{~min}$ utes), glucagon (serum cortisol level; $26.0 \mu \mathrm{g} / \mathrm{dL}$ at $0 \mathrm{~min}-$ ute, peak level of $26.7 \mu \mathrm{g} / \mathrm{dL}$ reached after 60 minutes), or a $\beta$-adrenergic agonist (serum cortisol level; $27.7 \mu \mathrm{g} / \mathrm{dL}$ at 0 minute, peak level of $27.2 \mu \mathrm{g} / \mathrm{dL}$ reached after 60 minutes) could not stimulate cortisol secretion. Abdominal computed tomography (CT) with contrast-enhancing medium revealed enlarged bilateral adrenal glands with multiple small nodules (measuring from 5-10 $\mathrm{mm}$ in diameter). A CT scan showed the right adrenal gland to be smaller than the left adrenal gland; using a volume rendering method, the right adrenal gland was $6.58 \mathrm{~cm}^{2}$ while left adrenal gland was $11.48 \mathrm{~cm}^{2}$ (Fig. 1). Fig. 2 shows a single photon emission computed tomography (SPECT) image of ${ }^{131} \mathrm{I}$-adosterol scintigraphy using the SPECT/CT system (Precedence 16, Philips), which visualizes the bilateral adrenal uptake. In transverse SPECT images, the total uptake values of regions of interest (ROIs) and the mean values (mean $\pm \mathrm{SD}$ ) for the right and left adrenal glands were 24,826 and 18,879 counts and $147 \pm 68.3$, $125 \pm 51.3$ counts, respectively. 
(a)

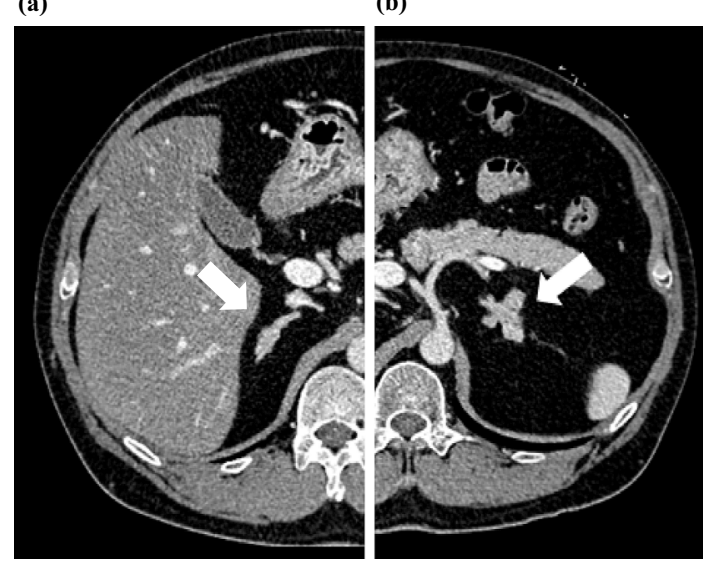

Figure 1. Abdominal computed tomography with contrastenhanced medium shows enlarged bilateral adrenal glands (arrows) with multiple small nodules. Right (a) and left adrenal glands (b) show the central area of both adrenal glands.

The bone mineral density in his lumbar spine had decreased to $0.819 \mathrm{~g} / \mathrm{cm}^{2}$. Magnetic resonance imaging (MRI) examination of the head revealed the presence of a Rathke's cleft cyst, but no tumor in the pituitary gland.

Based on these results, we made a diagnosis of Cushing's syndrome due to bilateral nodular adrenocortical disease, bilateral macronodular adrenal hyperplasia (BMAH) or PPNAD. Because of the endocrinological data, the adrenal gland CT results, and the family history, we considered that his hypercortisolism may have been due to PPNAD. PPNAD is reported to be associated with CNC. Therefore, we examined the heart, thyroid, mammary gland, and testis, but we detected no additional features that were specific for CNC.

We planned a two-step operation after obtaining the patient's consent; first, unilateral adrenalectomy, which would enable a more accurate diagnosis by histological examinations, and then adrenalectomy of the other side. Although the size of the right adrenal gland was smaller than that of the left, the ROI values of the right adrenal gland were higher than those of the left. Therefore, we first performed laparoscopic right adrenalectomy in April 2013. Macroscopically, adrenal cortex cross-sections contained multiple blackish brown nodules ranging in size from 2 to $10 \mathrm{~mm}$ in diameter. Microscopically, hematoxylin and eosin-stained specimens revealed that cortical nodules contained compact cells with eosinophilic cytoplasm and focal lymphocytic infiltration or lipomatous degeneration. The internodular cortex was also markedly atrophic (Fig. 3). 3 $\beta-H S D, c 17, c 21$, and DHEA-ST immunoreactivity was markedly detected in all of the cortical nodules.

These histopathological findings were closely consistent with PPNAD and clearly differentiated the patient's condition from adrenocortical adenomas both macro- and microscopically. After the right adrenalectomy, the serum cortisol and urinary free cortisol excretion levels in excess of the normal upper limits were observed to decrease by about half, but the Cushingoid appearance did not disappear. For
Cushing's syndrome due to PPNAD, bilateral adrenalectomy was recommended except for patients who are asymptomatic or only minimally symptomatic (2). Thus, a left adrenalectomy was proposed. However, after the first operation the patient suffered both deep vein thrombosis and pulmonary thrombosis and therefore was treated with anticoagulant therapy. During the treatment and before the second operation, adrenal insufficiency was not observed and corticosteroid replacement therapy was not needed.

Two months later, left adrenalectomy was performed. The histopathological findings were essentially the same as those in the right adrenal gland described above. After both adrenalectomies, he was administered $20 \mathrm{mg}$ of hydrocortisone daily as hormone replacement therapy. An analysis of the patient's genomic DNA obtained from his peripheral blood identified a p.E17X (c.49G $>$ T) mutation in PRKAR1A, which encodes type $\mathrm{I} \alpha$ regulatory subunit of protein kinase A (Fig. 4). The same point mutation in PRKARIA was also found in his mother. However, she did not show any signs of either hypertension, hypercortisolism, or adrenal hyperplasia on the CT scan, and also had no manifestation of CNC. We did not perform a mutation analysis of the patient's cousin. The patient is now vigorous and active, and the hypertension has improved under hormone replacement treatment.

\section{Discussion}

In this report, we present a patient with PPNAD and $\mathrm{CNC}$, which is a rare cause of Cushing's syndrome, and we detected the presence of a novel mutation in the PRKARIA gene. PPNAD is a bilateral adrenocortical disorder harboring multiple black or brown cortical nodules associated with ACTH independent Cushing's syndrome. In the majority of the cases reported, this disease is well known to occur as a part of CNC in those younger than 30 years of age. CNC is an autosomal dominant disease first reported by Carney et al. in 1985 as a complex condition of spotty pigmented lesions of the skin, myxomatous masses, such as cardiac myxoma, cutaneous myxoma, and mammary myxoid fibroadenoma, and endocrine disorders, including PPNAD, testicular or ovarian tumors, and growth hormone-producing pituitary adenoma (1). The diagnostic criteria of CNC were finally formalized in 2001 (3). According to these criteria, patients could be diagnosed to have CNC if they match two major criteria or one major criterion plus one supplementary criterion, as summarized in Table 2. The patient in this report matched CNC with one major criterion, Cushing's syndrome due to PPNAD, and a supplementary criterion, genomic abnormality of PRKARIA. However it is not always easy to establish the diagnosis of PPNAD and CNC. In our case, there were confusing results from both the endocrinological tests and imaging studies.

Our patient presented with a clinically apparent Cushingoid appearance with the autonomous and excessive production of cortisol, suppressed ACTH levels, and bilateral adre- 
(a)

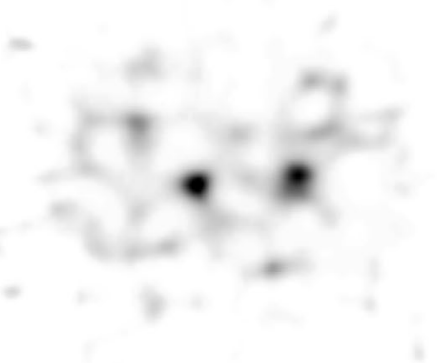

(b)

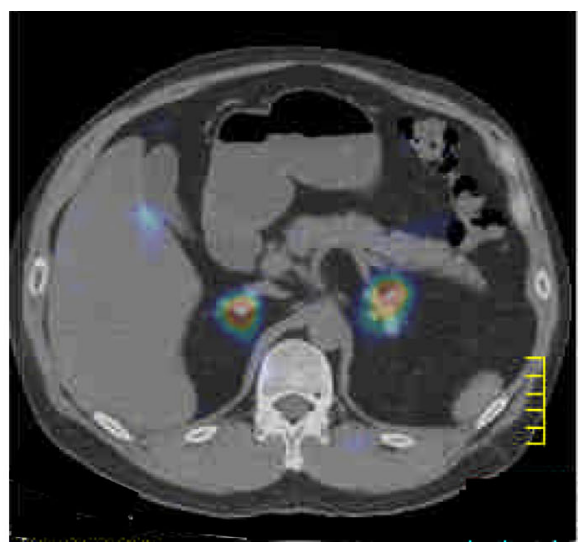

Figure 2. (a) SPECT image of ${ }^{131}$ I-adosterol scintigraphy shows a bilateral adrenal uptake. (b) Fusion image of SPECT and CT.

(a)

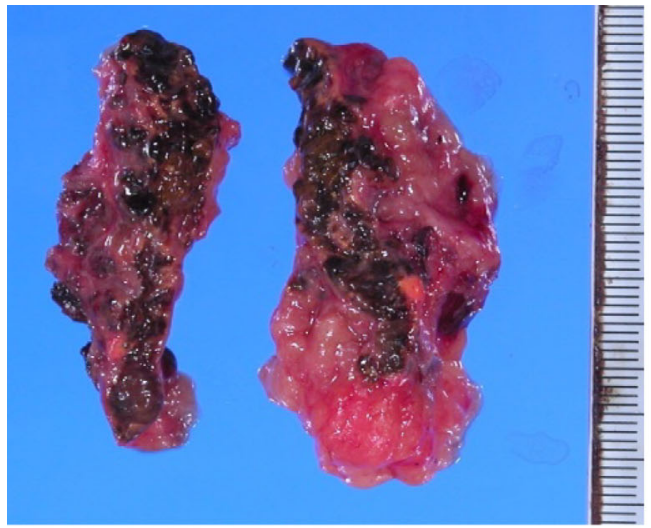

(c)

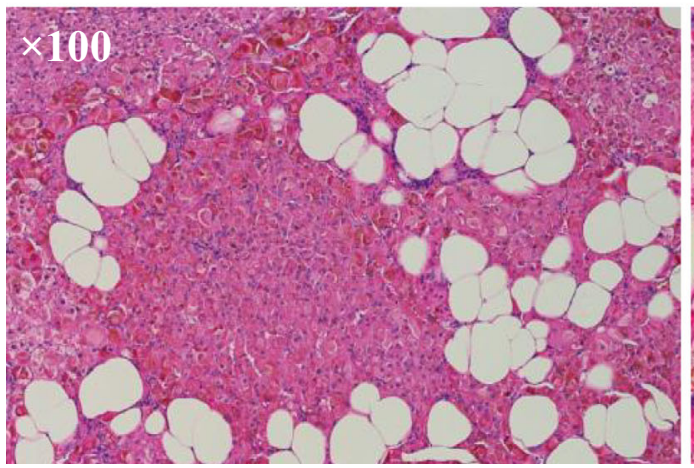

(b)

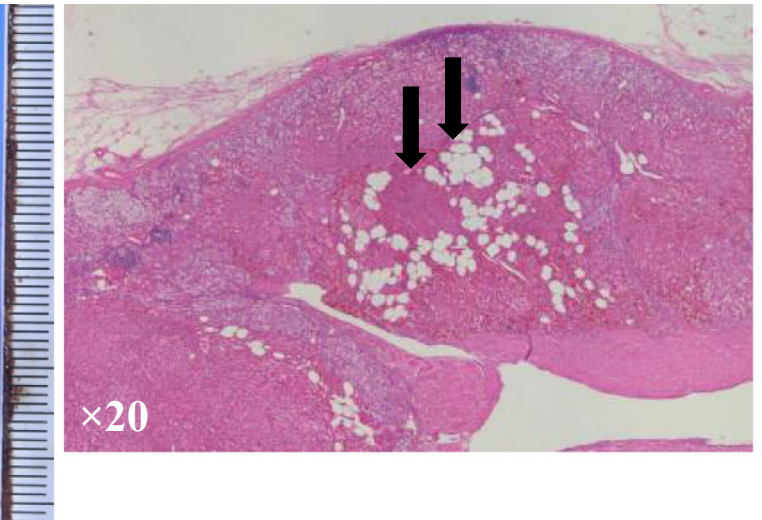

(d)

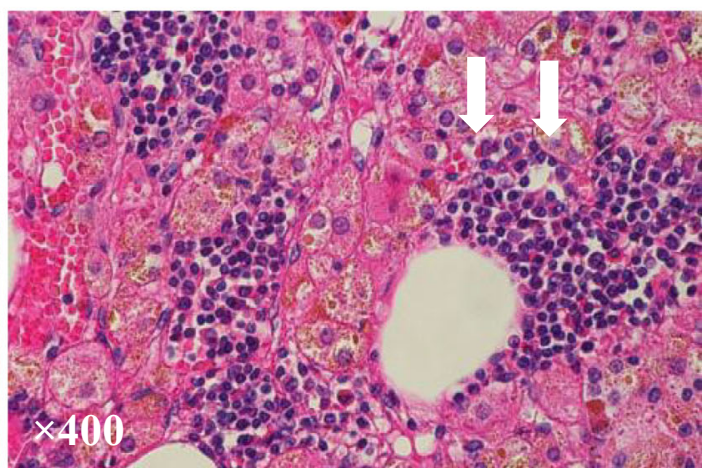

Figure 3. A transverse section showing the macroscopic appearance of the right adrenal gland. Multiple blackish brown nodules are present in the adrenal cortex (a). Hematoxylin and Eosin staining sections of the right adrenal gland: magnification $\times 20$ (b), $\times 100$ (c) and $\times 400$ (d). Nodules contain compact cells with eosinophilic cytoplasm and display focal lymphocytic infiltration (white arrows) or lipomatous degeneration (black arrows).

nal enlargement with multiple nodules. Among the causes of Cushing's syndrome, BMAH and PPNAD are rare types of nodular adrenocortical disease that are usually bilateral. BMAH is a disorder previously referred to as ACTHindependent bilateral macronodular adrenal hyperplasia (AIMAH) (4). BMAH is characterized by massive bilateral enlargement of the adrenal glands with large nodules, and when the diameter of such large adrenal nodules surpass 5 $\mathrm{cm}$, then they are considered to be specific for BMAH (5). PPNAD, meanwhile, is characterized by multiple small pigmented cortical nodules of bilateral adrenal glands. CT scans usually revealed adrenal glands harboring PPNAD to appear rather normal or at best slightly lumpy because of the surrounding atrophy, and to be by no means en- 

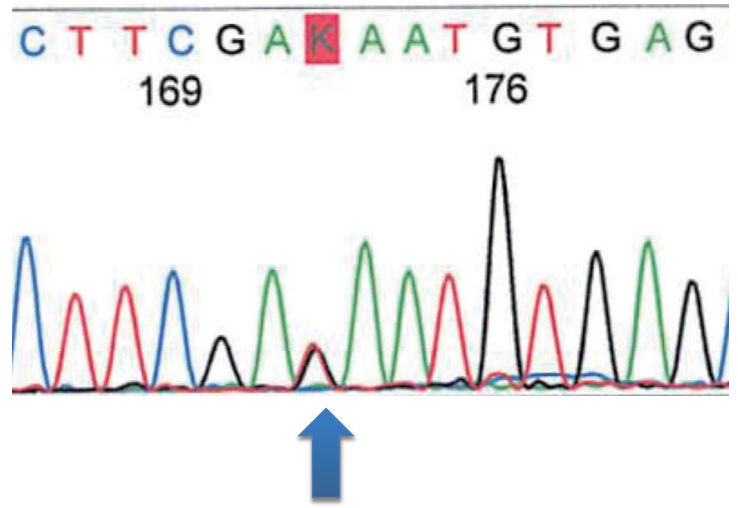

\section{c.49G $>\mathrm{T}$}

1516171819

-L--R--E--C--ECTTCGAGAATGTGAG CTTCGATAATGTGAG -L--R--X-

Figure 4. A sequence analysis of the type I $\alpha$ regulatory subunit of protein kinase A (PRKAR1A) gene from the patient's genomic DNA shows a p.E17X (c.49G $>$ T) mutation.

Table 2. Diagnostic Criteria for CNC (Ref 3).

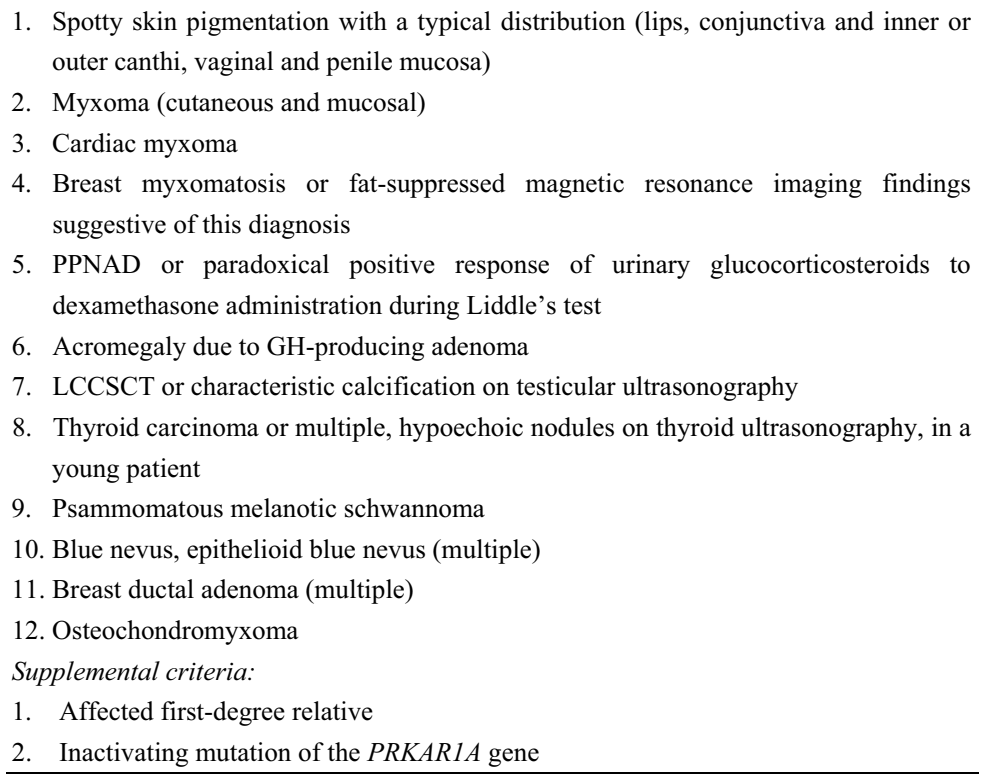

larged (6). In our patient, the CT findings revealed the bilateral adrenal glands to be enlarged with multiple small nodules.

Therefore, we could not determine the clinical diagnosis of BMAH or PPNAD for this patient by CT imaging alone. In order to discern between these two bilateral nodular adrenocortical disorders, we performed several endocrinological tests. The patients with PPNAD were reported to exhibit a paradoxical increase of cortisol secretion in response to a 6-day Liddle test (7). In this test, increased urinary free cortisol excretion on the 5th and 6th days that is $50 \%$ higher than the basal level did support the diagnosis of PPNAD. In our case, a paradoxical response was not detected. However, a paradoxical response to dexamethasone is not always specific for PPNAD and such findings have been reported in only $69 \%$ of the patients with PPNAD (7). Furthermore, recent studies demonstrated that in BMAH, several hormones, such as glucose-dependent insulinotropic polypeptide (GIP), AVP, GnRH, glucagon, or epinephrine, could stimulate cortisol secretion via an aberrant expression of respective receptors on hyperplastic adrenal cells (8). However, in this patient, no hormone except for ACTH was able to stimulate cortisol secretion.

Important evidence for defining the patient's diagnosis was that the patient's cousin on his mother's side had been diagnosed with Cushing's syndrome due to histologically confirmed PPNAD and breast adenoma. These features met the criteria for $\mathrm{CNC}$ despite the absence of a genomic analysis. After adrenalectomy, histological examinations showed small, multiple blackish brown nodules in the cortex of the adrenal glands, which were compatible with PPNAD. An analysis of the genomic DNA from the peripheral blood identified a p.E17X (c.49G $>\mathrm{T})$ mutation in the PRKARIA gene in both the patient and his mother.

PPNAD is the most frequent endocrine manifestation of $\mathrm{CNC}$, and there is a bimodal age distribution for PPNAD among CNC patients. A minor peak occurs at 2-3 years of age, and the major peak is in the second and third decades 
of life (3). Our patient was diagnosed at 40 years of age. He had suffered from hypertension and dyslipidemia for 6 years prior to our assessment, and had a history of multiple rib fractures of both sides without any knowledge of how these injuries occurred, which suggested that the onset of PPNAD occurred in his second or third decade. Although his mother had the same point mutation in the PRKARIA gene, she had no hypertension, hypercortisolism, or adrenal hyperplasia on CT scans, and had no manifestation of CNC. It is difficult to establish a diagnosis of PPNAD because the associated hypercortisolism develops slowly and thus the clinical features of Cushing's syndrome can be overt, subclinical, or latent (9); however, it is also reported that autopsies of patients with CNC show PPNAD in almost all cases (3) and penetrance for CNC due to PRKARIA mutations is close to $100 \%$ (10). As a result, it was considered likely that both the patient and his mother had PPNAD, and that this disease had become overt in him, but remained latent in his mother.

$\mathrm{CNC}$ is inherited in an autosomal dominant manner, and some responsible genes have been identified, such as PRKAR1A, phosphodiesterase (PDE)-11A, and PDE$8 B$ (11). Among them, PRKARlA, at $17 \mathrm{q} 24.2$, is the major gene responsible for $\mathrm{CNC}$ and it was found to be mutated in approximately half of all known CNC kindred (3). PRKAR1A, which encodes the type $1 \alpha$ regulatory subunit of protein kinase A, is a known tumor suppressor gene, and Kirschner et al. detected the loss of heterozygosity (LOH) in the vicinity of PRKARIA in CNC cases (12). In our case, a novel mutation (c.49G $>\mathrm{T}$ ) was located in exon 2 of PRKAR1A, which leads to a premature stop codon. Although the genotype-phenotype correlation is not certain for $\mathrm{CNC}$ patients, Bertherat et al. also reported that those who had a PRKARIA mutation were more likely to have myxomas, pigmented skin lesions, and thyroid or gonadal tumors (13). In addition, Breassoulis et al. reported the characteristics of seven CNC patients with strokes and cardiac myxomas. All of these patients were female and four were diagnosed with Cushing's syndrome due to PPNAD. In five of them, a PRKARIA mutation was identified and all mutations were located in exons 3-5 or introns 2-3, and all led to a nonsense PRKARlA mRNA (14). However, it is considered to be clinically more important to determine whether such patients have cardiac myxoma or not, because this condition is fatal in half of cases with heart-related problems, such as cardiac myxoma, cardiac myxoma emboli, and arrhythmia (3).

In conclusion, we detected a novel mutation, p.E17X (c.49G $>$ T) in PRKAR1A, in a patient with PPNAD. Because PPNAD can be overt, subclinical, or latent, it is sometimes difficult to establish the diagnosis of PPNAD. We should perform careful medical examinations, not only in the patient, but also in their family members. In our case, except for PPNAD, no additional manifestations of $\mathrm{CNC}$ have been detected, however, we must continue to assess him, paying particular attention to any cardiac pathology.

The authors state that they have no Conflict of Interest (COI).

\section{References}

1. Carney JA, Gordon H, Carpenter PC, Shenoy BV, Go VL. The complex of myxomas, spotty pigmentation, and endocrine overactivity. Medicine (Baltimore) 64: 270-283, 1985.

2. Carney JA, Young WF. Primary pigmented nodular adrenocortical disease and its associated conditions. Endocrinologist 2: 6-21, 1992.

3. Stratakis CA, Kirschner LS, Carney JA. Clinical and molecular features of the Carney complex: diagnostic criteria and recommendations for patient evaluation. J Clin Endocrinol Metab 86: 40414046, 2001.

4. Louiset E, Duparc C, Young J, et al. Intraadrenal corticotropin in bilateral macronodular adrenal hyperplasia. N Engl J Med 369: 2115-2125, 2013.

5. Doppman JL, Chrousos GP, Papanicolaou DA, Stratakis CA, Alexander HR, Nieman LK. Adrenocorticotropin-independent macronodular adrenal hyperplasia: an uncommon cause of primary adrenal hypercortisolism. Radiology 216: 797-802, 2000.

6. Groussin L, Cazabat L, René-Corail F, Jullian E, Bertherat J. Adrenal pathophysiology: Lessons from the Carney complex. Horm Res 64: 132-139, 2000.

7. Stratakis CA, Sarlis N, Kirschner LS, et al. Paradoxical response to dexamethasone in the diagnosis of primary pigmented nodular adrenocortical disease. Ann Intern Med 131: 585-591, 1999.

8. Libé R, Coste J, Guignat L, et al. Aberrant cortisol regulations in bilateral macronodular adrenal hyperplasia: a frequent finding in a prospective study of 32 patients with overt or subclinical Cushing's syndrome. Eur J Endocrinol 163: 129-138, 2010.

9. Sarlis NJ, Chrousos GP, Doppman JL, Carney JA, Stratakis CA. Primary pigmented nodular adrenocortical disease: reevaluation of a patient with carney complex 27 years after unilateral adrenalectomy. J Clin Endocrinol Metab 82: 1274-1278, 1997.

10. Kirschner LS, Sandrini F, Monbo J, Lin JP, Carney JA, Stratakis CA. Genetic heterogeneity and spectrum of mutations of the PRKAR1A gene in patients with the Carney complex. Hum Mol Genet 9: 3037-3046, 2000.

11. Horvath A, Bertherat J, Groussin L, et al. Mutations and polymorphisms in the gene encoding regulatory subunit type 1-alpha of protein kinase A (PRKAR1A): an update. Hum Mutat 31: 369-379, 2010.

12. Kirschner LS, Carney JA, Pack SD, et al. Mutations of the gene encoding the protein kinase A type I- $\alpha$ regulatory subunit in patients with the Carney complex. Nat Genet 26: 89-92, 2000.

13. Bertherat J, Horvath A, Groussin L, et al. Mutations in regulatory subunit type 1A of cyclic adenosine 5'-monophosphate-dependent protein kinase (PRKAR1A): phenotype analysis in 353 patients and 80 different genotypes. J Clin Endocrinol Metab 94: 2085-2091, 2009.

14. Briassoulis G, Kuburovic V, Xekouki P, et al. Recurrent left atrial myxomas in Carney complex: a genetic cause of multiple strokes that can be prevented. J Stroke Cerebrovasc Dis 21: 914.e1914.e8, 2012.

The Internal Medicine is an Open Access article distributed under the Creative Commons Attribution-NonCommercial-NoDerivatives 4.0 International License. To view the details of this license, please visit (https://creativecommons.org/licenses/ by-nc-nd/4.0/).

(C) 2016 The Japanese Society of Internal Medicine

http://www.naika.or.jp/imonline/index.html 